\title{
PENGARUH PROMSI DAN ATRIBUT PRODUK TERHADAP KEPUTUSAN PEMBELIAN SEPATU SNEAKERS (Studi pada konsumen Bjo SneakersMind di Kota Malang)
}

\author{
Muhammad Rizky Nopeyandi \\ Department of Management FEB UMM \\ E-mail : nopeyandirizky@gmail.com
}

\begin{abstract}
This study aims to examine the effect of promotion and product attributes (consisting of brand, product quality, product features, product design, labels, warranties, and complementary services) to consumers' buying decisions as sneakers Bjo SneakersMind in Malang. Analytical techniques used are multiple linear regression analysis and classical assumption test. From the data collected by using the questionnaire (questionnaire) with the number of samples of 100 respondents. The results show that promotion (through electronic media, print media, and personal sales) and product attributes (consisting of brand, product quality, product features, product design, labels, guarantee and complementary services) have a positive and significant effect on purchasing decisions Sneakers on Bjo SneakersMind consumers.
\end{abstract}

Keywords: promotion, product attributes, consumers' buying.

\section{PENDAHULUAN}

Perilaku konsumen sangat memiliki peranan yang penting dalam penentuan proses pengambilan keputusan pembelian, proses tersebut merupakan suatu pendekatan penyelesaian masalah yang mempunyai tahapan mulai dari pengenalan kebutuhan, pencarian informasi, penilaian dan evaluasi, keputusan pembelian, dan perilaku pasca pembelian (Kotler dan Amstrong, 2010).

Konsumen dalam memilih produk tentu saja akan dipengaruhi atribut produk dan juga proses promosi penjualan. Selain itu atribut produk dan promosi penjualan juga mendapat peran penting dalam proses konsumen akan melakkukan proses keputusan pembelian.

Keputusan pembelian itu sendiri sebuah tahapan pembeli telah menentukan pilihannya kemudian melakukan pembelian produk, serta mengkonsumsinya (Suharno, 2010). Keputusan pembelian juga dapat dilakukan oleh seorang konsumen dengan atas dasar keinginan dan kebutuhannya terhadap suatu produk.

Hal ini tentu akan terlihat dari unsur-unsur sebuah produk yang dipandang penting oleh konsumen dan dijadikan dasar pengambilan keputusan. Atribut produk itu sendiri merupakan sebagai karakteristik atau ciri-ciri yang melekat terhadap produk seperti merek, kualitas 
produk, fitur produk, gaya atau desain produk, jaminan, dan layanan pelengkan yang ditawarkan.

Atribut produk sangat penting karena atribut produk temtu selalu mendapatkan perhatian, permintaan, pemakaian, atau dikonsumsi untuk dapat memenuhi keinginan serta kebutuhan konsumen (Kotler dan Amstrong, 2010).

Pertimbangan tentang pilihan atribut-atribut dari suatu produk yang ada tentu sangat membantu konsumen membuat keputusan yang tepat, sehingga konsumen bisa mendapatkan apa yang ingin dicapai dari produk tersebut. Atribut produk akan mulai dipertimbangkan oleh konsumen sebagai informasi untuk membuat keputusan yang rasional.

Menurut Yunita dan Haryanto (2012) menunjukkan bahwa atribut produk mempunyai pengaruh positif dan signifikan terhadap keputusan pembelian produk es krim magnum di Indonesia. Hasil penelitian ini menunjukkan bahwa suatu produk yang memiliki kualitas atribut produk yang bagus maka konsumen tentu akan melakukan proses melakukan keputusam pembelian produk tersebut.

Produk memiliki atribut atau sifat-sifat yang sesuai dengan apa yang diharapkan oleh pembelinya maka dari itu suatu produk tersebut akan dianggap pas dan tentu kosnumen akan melakukan tindakan keputusan pembelian (Wahyudi, 2005). Konsumen di samping melihat sebuah atribut produk yang terkandung, konsumen juga akan melihat dari sebauh faktor proses strategi promosi dalam pengambilan keputusan pembelian.
Proses promosi memiliki peranan yang penting karena dalam mengkomunikasikan produk kepada konsumen melalui kegiatan promosi penjualan juga merupakan sauatu hal yang penting. Adanya suatu kegiatan promosi, tentu akan membuat cepat para konsumen akan mengetahui baik atau buruknya yang ditawarkan oleh suatu produk tersebut.

Promosi memiliki peranan kuat agar suatu produk dapat dikenal konsumen. Promosi itu sendiri merupakan suatu kegiatan menyebarkan sebuah informasi untuk membuat konsumen menjadi terpengaruh terhadap produknya agar bersedia untuk menerima, mekalukan pembelian, dan loyal terhadap produk yang ditawarkan (Tjiptono, 2008:219).

Menurut Prasetyo dan Wahyuati (2015) dalam penelitiannya di Cafe Kopiganes bahwa promosi berpengaruh terhadap keputusan pembelian. Dalam penelitian ini bahwa kegiatan promosi yang baik tentu akan membuat konsumen tertarik dan tentu akan melakukan proses keputusan pembelian terhadap produk.

Penggunaan sosial media sebagai media promosi tentu sangat berperan dalam membangun hubungan sosial yang lebih personal dan dinamis sehingga sangat cocok untuk media promosi kepada khalayak luas dengan ceapt. Kegiatan promosi menggunakan sosial media berpusat pada usaha membuat suatu konten yang menarik perhatian dan membuat pembaca merasa tertarik untuk melihat konten tersebut. 
Sepatu sneakers sendiri berasal dari luar negeri yakni amerika serikat pada akhir tahun 1800 an, dan Keds merupakan sebuah perusahaan yang bergerak dibidang produksi sepatu sneakers berbahan kanvas secara massal mulai sampai sekarang.

Istilah dari jenis sneakers itu sendiri muncul karena dengan menggunakan sepatu sneakers, akan membuat langkah kaki kita tak bersuara seolah-olah seperti menyelinap (Sneak). Seperti sepatu atletik, sepatu ini dibuat dengan sol yang lentur, terbuat dari karet atau bahan sintetis, dan bagian atas terbuat dari kanvas. Sepatu sneakers juga lebih menekankan kepada aspek fisik yang santai sehingga mampu meningkatkan percaya diri si pengguna.

Bjo SneakersMind salah satu yang memanfaatkan peluang tersebut yakni dengan menjual produknya melalui online dan juga tidak lupa memiliki kios tetap di dearah kota Malang, Bjo SneakersMind menjual berbagai jenis sepatus sneakers dengan merk-merk ternama dan kualitas original. Dalam proses pemasarannya dan promosinya Bjo SneakersMind menjual produknya melalui internet khususnya media sosial yakni menggunakan akun facebook dan akun instagram.

Berdasarkan paparan tersebut, perumusan masalah yaitu: (1) Apakah promosi berpengaruh terhadap keputusan pembelian sepatu sneakers? (2) Apakah atribut produk berpengaruh terhadap keputusan pembelian sepatu sneakers? (3) Variabel mana yang memiliki kontribusi terbesar terhadap keputusan pembelian sepatu snekaers?
Tujuan yang ingin dicapai untuk mengetahui pengaruh promosi terhadap keputusan pembelian konsumen sepatu sneakers, untuk mengetahui pengaruh atribut produk terhadap keputusan pembelian konsumen sepatu sneakers, untuk mengetahui variabel mana yang memiliki kontribusi terbesar terhadap keputusan pembelian sepatu sneakers.

\section{KAJIAN PUSTAKA}

Keputusan Pembelian merupakan sebuah tahapan seorang konsumen menentukan pilihannya dan melakukan pembelian produk, serta menggunakan produk tersebut (Suharno, 2010). Menurut Kotler dan Keller (2007:214) juga menyatakan bahwa suatu konsumen dalam melakukan pengambilan keputusan melalui sebuah proses psikologis dasar yang memainkan peranan penting dalam bagaimana konsumen secara aktual mengambil keputusan pembelian.

Menurut Kotler dan Keller (dalam Sudarsono dan Kurniawati, 2013:20) proses pengambilan keputusan pembelian yang akan dilakukan oleh konsumen merupakan indikator keputusan pembelian, yaitu: a) pengenalan masalah, b) pencarian informasi, c) evaluasi alternatif, d) keputusan pembelian, e) perilaku pasca pembelian. Hal diatas dapat dan dari uraian tersebut maka indikator keputusan pembelian yang digunakan pada penelitian ini meliputi: Kemantapan pada sebuah produk, dan Keyakinan hati dalam melakukan keputusan pembelian.

Menurut Swastha (2007) Promosi merupakan sebuah proses komunikasi perusahaan dengan 
konsumennya, melalui berbagai macam media yang dilakukan oleh perusahaan agar mendapatkan perhatian mereka dan persepsi baik dari mereka.

menurut Tjiptono (2002) promosi juga merupakan suatu kegiatan pemasaran yang memberikan sebuah informasi agar konsumen dapat terpengaruhi atau dalam hal peningkatan pasar sasaran atas perusahaan dan produknya agar para konsumen bersedia menerima, melakuan pembelian, dan loyal pada produk yang ditawarkan perusahaan.

Promosi itu sendiri merupakan kombinasi dari periklanan, personal selling dan strategi promosi yang semuanya ditujukan untuk mencapai tujuan dari perusahaan. Menurut Kotler dan Armstrong (2001) dimensi variabel-variabel yang ada di dalam promotional mix ada empat, yaitu: a) periklanan, b) penjualan personal, c) promosi penjualan, d) penjualan langsung.

Dari hal diatas dan uraian tersebut maka indikator promosi digunakan pada penelitian ini meliputi : kualitas dari iklan di media (elektronik dan cetak), kuantitas penyampaian isi pesan di media promosi (elektronik dan cetak) dan penyampaian informasi melalui penjualan personal.

Kotler \& Amstrong (2010) menyatakan ada beberapa atribut yang menyertai dan melengkapi dalam pengembangan suatu produk atau jasa melibatkan dari manfaat yang akan didapatkan oleh konsumen terhadap produk atau jasa tersebut. Manfaat tersebut terdapat pada atribut produk seperti kualitas, fitur, serta gaya dan desain. Sedangkan menurut Tjiptono (2008:104) menambahkan beberapa karakteristik dari atribut produk, bahwa atribut produk juga seperti merek, jaminan (garansi), pelayanan, dan sebagainya.

Kerangka pikir berfungsi untuk mempermudah dan memberikan gambaran penelitian yang akan dilakukan yaitu pengaruh promosi dan atribut produk terhadap keputusan pembelian sepatu sneakers. Berdasarkan teori, maka kerangka pikir penelitian ini:

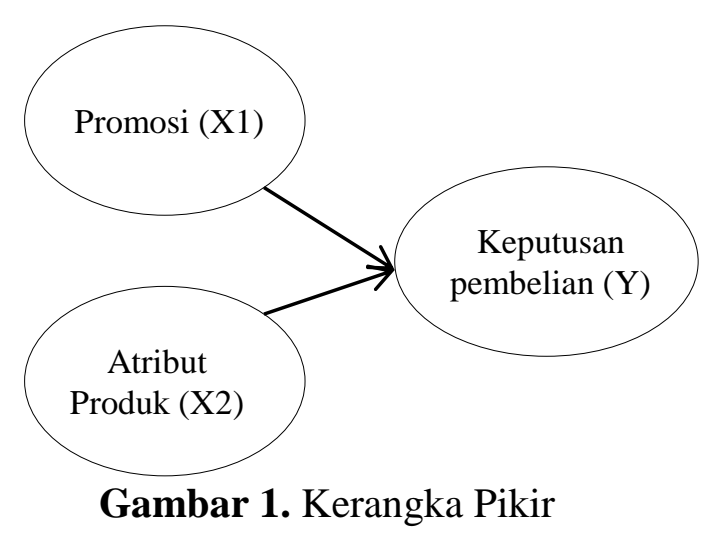

Berdasarkan kerangka pikir di atas menunjukkan bahwa promosi dan atribut produk yang diberikan perusahaan kepada konsumen akan mempengaruhi keputusan pembelian. Jika promosi penjualannya tinggi maka akan dapat menimbulkan proses keputusan pembelian. Begitu pula jika atribut produk yang baik dari perusahaan akan dapat menimbulkan persepsi baik dan menimbulkan keputusan pembelian dari konsumen.

\section{METODE PENELITIAN}

Lokasi penelitian yang peneliti lakukan adalah di Bjo SneakersMind di Kota Malang yang terletak di Jl. Jl. Puncak Borobudur (dekat SMAN 9 Malang), Mojolangu, Kec. Lowokwaru, kota Malang, Jawa 
Timur, 65153. Jenis pelitian yang digunakan yaitu penelitian deskriptif yang menggunakan metode survei dan penyebaran kuesioner.

Sumber ada yang digunkana terdiri dari sumber data, yakni data primer diperoleh dari hasil pengisian kuesioner oleh konsumen Bjo SneakersMind dan data sekunder berupa informasi tentang konsumen bjo SneakersMind.

Populasi yaitu digunakan tidak dapat diketahui jumlah pastinya makanya di tentukan menentukan jumlah sampel menggunakan pengambilan sempel sehingga dihasilkan sampel sebanyak 100 responden dengan menggunakan teknik purposive sampling yaitu adanya kriteria yang dijadikan sampel dalam penelitian ini yaitu konsumen yang pernah melakukan pembelian baik secara online maupun langsung data ke toko mereka. Metode analisa data dalam penelitian ini adalah analisis regresi berganda, uji asumsi klasik, koefisien determinasi, uji f, uji $\mathrm{t}$ dan uji kontribusi terbesar.

\section{HASIL PENELITIAN DAN PEMBAHASAN}

Data yang didapatkan dari jawaban responden terhadap kuesioner kemudian dilakukan analisis dengan pendekatan statistik menggunakan bantuan software SPSS. Hasil analisis data tersebut akan tampilkan pada tabel - tabel dan dijelaskan sebagai berikut..

Tabel 1. Hasil Regresi linear berganda

\begin{tabular}{lcccc}
\hline \multicolumn{1}{c}{ Variabel } & $\begin{array}{c}\text { Koefisien } \\
\text { Regresi (b) }\end{array}$ & t-Hitung & Sig & Keterangan \\
\hline Konstanta & 1,608 & & & \\
Promosi $\left(\mathrm{X}_{1}\right)$ & 0,147 & 4,424 & 0,000 & Signifikan \\
Atribut produk $\left(\mathrm{X}_{2}\right)$ & 0,061 & 3,729 & 0,000 & Signifikan \\
\hline
\end{tabular}

Hasil pengujian regresi linear berganda dengan rumus: $Y=\alpha+b_{1}$ $\mathrm{X}_{1}+\mathrm{b}_{2} \mathrm{X}_{2}+\mathrm{e}$ menunjukkan nilai konstanta sebesar positif 1,608, artinya apabila variabel bebas (promosi dan atribut produk) dianggap konstan atau bernilai nol, maka akan terjadi keputusan pembelian sepatu sneakers pada konsumen Bjo SneakersMind.

Variabel promosi memiliki koefisien regresi sebesar positif 0,147. Dapat diartikan bahwa semakin tinggi penilaian mengenai promosi, maka semakin tinggi keputusan pembelian ataudengan kata lain semakin baik promosi maka semakin tinggi kecenderungan konsumen untuk membeli

Variabel atribut produk dengan koefisien regresi sebesar positif 0,061. Maka dapat diartikan bahwa atribut produk berpengaruh positif terhadap keputusan pembelian. Hal ini berarti jika semakin tinggi penilaian mengenai atribut produk, maka semakin tinggi akan terjadi keputusan pembelian.

Tabel 2. Koefisiean determinasi

\begin{tabular}{cc}
\hline $\mathrm{R}^{2}$ & Presentase \\
\hline 0,698 & $69,8 \%$ \\
\hline
\end{tabular}


Hasil perhitungan pada Tabel 2 menunjukkan bahwa koefisien determinasi yang diperoleh sebesar $\mathrm{R}^{2}=0,698$. Hal tersebut menunjukkan bahwa keputusan pembelian konsumen dipengaruhi oleh promosi dan atribut produk sebesar 69,8\% sedangkan sisanya sebesar $30,2 \%$ dipengaruhi oleh variabel lain diluar penelitian.

Tabel 3. Hasil uji F

\begin{tabular}{cccc}
\hline Nilai $\mathrm{F}_{\text {hitung }}$ & Nilai $\mathrm{F}_{\text {tabel }}$ & Sig. & Keterangan \\
\hline 115,491 & 3,09 & 0,000 & $\mathrm{H}_{0}$ Ditolak, $\mathrm{H}_{1}$ Diterima \\
\hline
\end{tabular}

Dari hasil uji F pada tabel diatas dengan menggunakan regresi sederhana didapatkan $F$ hitung sebesar 115,491 dengan tingkat signifikansi sebesar 0,000. Dari perhitungan $\mathrm{F}$ tabel yang sudah dilakukan, didapat nilai $\mathrm{F}$ tabel sebesar 3,09 yang nilainya lebih kecil dari Fhitung. Dengan demikian hipotesis satu dapat diterima.

Tabel 4. Hasil uji T

\begin{tabular}{cccc}
\hline Nilai $\mathrm{T}_{\text {hitung }}$ & Nilai $_{\text {tabel }}$ & Sig. & Keterangan \\
\hline 4,424 & 1,660 & 0,000 & $\mathrm{H}_{0}$ Ditolak, $\mathrm{H}_{1}$ Diterima \\
3,729 & 1,660 & 0,000 & $\mathrm{H}_{0}$ Ditolak, $\mathrm{H}_{1}$ Diterima \\
\hline
\end{tabular}

Dari uraian hasil $\mathrm{T}$ hitung dan $\mathrm{T}$ tabel di atas maka dapat diuraikan hasil analisis secara parsial yaitu pengaruh variabel promosi (X1) dan atribut produk (X2) terhadap keputusan pembelian (Y) dari hasil perhitungan parsial menunjukkan bahwa pada taraf nyata $5 \%(\alpha=$ $0,05)$ diperoleh nilai Ttabel sebesar 1,660 .

Dengan pengujian statistik didapat nilai Thitung variabel promosi sebesar 4,424. Karena nilai $\mathrm{T}$ hitung > dari $\mathrm{T}$ tabel $(4,424>$ 1,660) maka dapat diartikan bahwa secara parsial variabel promosi (X1) berpengaruh terhadap keputusan pembelian sepatu sneakers pada konsumen Bjo SneakersMind di Kota Malang (Y).

Dari uraian hasil $\mathrm{T}$ hitung dan $\mathrm{T}$ tabel pada tabel di atas maka dapat diuraikan nilai $\mathrm{T}$ hitung variabel atribut produk sebenar 3,729. Karena nilai $\mathrm{T}$ hitung > dari Ttabel $(3,729>$
1,660) maka dapat diartikan bahwa secara parsial variabel atribut produk (X2) berpengaruh terhadap keputusan pembelian sepatu sneakers pada konsumen Bjo Sneakers di Kota Malang.

\section{SIMPULAN}

Promosi berpengaruh positif dan signifikan terhadap keputusan pembelian sepatu sneakers pada konsumen Bjo SneakersMind di Kota Malang. Atribut produk berpengaruh positif dan signifikan terhadap keputusan pembelian sepatu sneakers pada konsumen bjo SneakersMind di Kota Malang. Variabel yang Memiliki kontribusi terbesar berpengaruh terhadap keputusan pemblian sepatu snekaers pada konsumen Bjo SneakersMind di Kota malang adalah variabel promosi.

Bagi peneliti selanjutkan disarankan untuk dapat meneruskan atau mengembangkan penelitian ini 
dengan mencari faktor lain, menambahkan responden dan juga dapat meneliti kepada objek lain serta menggunakan teknik analisis yang berbeda sehingga dapat menyempurnakan penelitian ini.

\section{DAFTAR PUSTAKA}

Kotler, P. dan Amstrong, G . 2010. Principles Of Marketing. 13 Edition. New Jersey . Upper Saddle River: Pearson Prentice Hall.

2001. Manajemen pemasaraan. edisi Milennium. Jakarta: Prenhallindo.
Kotler, P. dan Keller, Kevin L. 2007. Manajemen Pemasaran, edisi 12, Jilid 1, Jakarta: PT.Indeks. Suharno. 2010. Marketing in Practice. edisi pertama. Yogyakarta: penerbit Graha Ilmu.

Swastha, Basu dan T. Hani Handoko. 2000. Manajemen Pemasaran, Analisis Perilaku Konsumen. Yogyakarta: BPPE.

Tjiptono, Fandy. 2006. Manajemen Jasa Edisi Pertama. Yogyakarta: Andi Offset. 2007. Strategi Pemasaran. Edisi Pertama. Yogyakarta: Andi. 